\title{
QUALIDADE DO CAFÉ-CEREJA DESCASCADO PRODUZIDO NA REGIÃO SUL DE MINAS GERAIS ${ }^{1}$
}

\section{Quality of the parchment coffee grown in the southern region of Minas Gerais}

\author{
Reginaldo Ferreira da Silva ${ }^{2}$, Rosemary Gualberto F. A. Pereira ${ }^{3}$, \\ Flávio Meira Borém ${ }^{4}$, Joel Augusto Muniz
}

\begin{abstract}
RESUMO
O café-cereja descascado vem conquistando cada vez mais espaço nas diversas regiões produtoras de café. Considerando os diversos questionamentos sobre a qualidade dos grãos resultantes desse tipo de processamento, os poucos estudos sobre o assunto e as contradições observadas nos resultados obtidos até o momento, com o presente estudo teve-se por objetivo caracterizar a qualidade do café-cereja descascado produzido na região sul do Estado de Minas Gerais, bem como averiguar a influência da altitude na qualidade desse café por meio de análises físicas, químicas e sensoriais das amostras em seu estado original e após a retirada de grãos defeituosos. Foram aleatoriamente selecionadas lavouras de empresas cafeeiras situadas em faixas de altitude que variaram de 720 a 920 metros e de 920 a 1120 metros. As amostras de café da safra 2001/2002 foram coletadas em 32 propriedades distribuídas em 10 municípios. No Pólo de Tecnologia em Qualidade do Café da Universidade Federal de Lavras (UFLA), foram realizadas as seguintes análises: teor de água, acidez titulável total, açúcares totais e análise sensorial. As análises físicas, químicas e sensoriais realizadas nos grãos de café demostraram que a maioria dos cafés descascados apresenta teor de água abaixo do valor recomendado; os valores médios de acidez titulável total e açúcares totais em todas as amostras analisadas encontram-se dentro dos valores característicos de bebidas finas; os cafés sem a presença dos defeitos, produzidos na faixa de altitude de 920 a 1120 metros, apresentam corpo e acidez mais fracos e doçura mais alta do que os produzidos na faixa de 720 a 920 metros; e que maiores altitudes possibilitam a produção de cafés de melhor qualidade.
\end{abstract}

TERMOS PARA INDEXAÇÃO: Qualidade, café descascado, defeito, altitude, sul de minas.

\begin{abstract}
The parchment coffee has been conquering more and more space in the several coffee growing regions. By taking into account the several questionings upon the quality of the berries resulting from this sort of processing, the few studies on the subject and the contradictions observed in the results obtained up to now, the present study aimed to characterize the quality of the parchment coffee produced in the Southern region of Minas Gerais state as well as to assess the influence of the altitude on the quality of these coffees by means of physical, chemical and sensorial analyses of the samples in their original state and after removal of defective beans. Crops of coffee enterprises situated in ranges of altitude varying from 720 to 920 meters and from 920 to 1120 meters were randomly selected. The coffee samples of the 2001/2202 crop were duly collected on 32 farms distributed in 10 towns. At the "Polo de Tecnologia em Qualidade do Café” of the "Universidade Federal de Lavras” (UFLA), the following analyses were performed: water content, total titrable acidity, total sugars and sensorial analyses. The physical, chemical and sensorial analyses accomplished on coffee beans showed that: most parchment coffees present water content bellow the value recommended; the average values of total titrable acidity and total sugars in all the samples analyzed lie within the values characteristic of fine beverages; hard beverage occurs in $75 \%$ of the parchment coffee samples with the presence of the defects; the coffees without the presence of the defects produced in the range of altitude of 920 to 1120 meters present body and acidity weaker and sweetness higher than the ones produced in the range of 720 to 920 meters; higher altitudes enable the production of better quality coffees.
\end{abstract}

INDEX TERMS: Quality, coffee parchment, altitude, defect, souther of minas.

(Recebido para publicação em 17 de dezembro de 2003 e aprovado em 22 de novembro de 2004)

\section{INTRODUÇÃO}

Ofertar qualidade ao consumidor brasileiro não tem sido uma tarefa fácil para os agentes envolvidos na cadeia produtiva, principalmente no que diz respeito ao retrospecto histórico do agronegócio café no Brasil, em razão de o mercado interno consumir cafés considerados de qualidade inferior aos de padrões de qualidade "especiais", que os classificam para as exportações. Entretanto, nos últimos 10 anos, o Brasil está começando a marcar lentamente presença no mundo dos cafés de qualidade.

A produção de café dirigida a esses mercados

1. Extraído da dissertação do primeiro autor para a obtenção do título de Mestre em Ciência dos Alimentos no Departamento de Ciência dos Alimentos da Universidade Federal de Lavras/UFLA, Caixa Postal 3037 - 37200-000 - Lavras, MG.

2. Mestrando do Departamento de Ciência dos Alimentos/UFLA. reginaldo.ferreira@posgrad.ufla.br

3. Farmacêutica, Ds, Professora Adjunta - DCA/UFLA. rosegfap@ufla.br

4. Engenheiro Agrícola, Ds, Professor Adjunto - Departamento de Engenharia/UFLA.

5. Engenheiro Agrônomo, Ds, Professor Titular - Departamento de Ciências Exatas/UFLA. 
diferenciados requer maior atenção e dedicação por parte do cafeicultor nas diversas etapas do sistema de produção, colheita e processamento, desde que os atuais procedimentos de avaliação comercial da qualidade do café sejam pautados nas características físicas, com a classificação pelo tipo, pela peneira, pela cor e pelos atributos sensoriais de sabor e aroma da bebida (BRASIL, 2003).

No Brasil, as primeiras pesquisas sobre a qualidade do café foram sobre a origem dos defeitos ou grãos imperfeitos, como os grãos pretos e ardidos. Em 1956, Bittancourt observou que a ocorrência de processos fermentativos durante o processamento dos grãos resultaria na formação de ácidos acético e lático, induzindo à formação de grãos pretos e à deterioração da qualidade (bebida rio).

Posteriormente, com outros estudos de pesquisas, tem-se verificado a influência dos defeitos nas propriedades físicas e químicas do café. Miya et al. (1973/1974), Pereira (1997) e Coelho (2000), verificaram que grãos verdes, pretos e ardidos depreciam a qualidade do café.

Apesar de existirem vários trabalhos sobre a qualidade dos cafés produzidos no sul de Minas, o processo denominado cereja descascado encontra-se em fase de expansão entre os produtores da região, exigindo maiores investimentos em pesquisas, com vistas a responder a diversos questionamentos sobre a qualidade dos grãos resultantes desse tipo de processamento.

O conceito do café-cereja descascado ou "CD" foi mencionado no início da década de 1950. Entretanto, a idéia permaneceu esquecida por quase 40 anos, até que passasse a ser aplicada, de forma independente, nos municípios de Botelhos e Ouro Fino, em Minas Gerais, nos anos de 1989 e 1990 (BRANDO, 1996). A partir daí, a metodologia passou a ser utilizada nos demais Estados e municípios brasileiros.

A Organização Internacional do Café (OIC, 1991), analisou as características sensoriais do cafécereja descascado, proveniente dos municípios de Mococa (SP), Botelhos (MG) e Apucarana (PR). No aspecto geral, as amostras analisadas apresentaram as maiores e melhores características sensoriais, como corpo, acidez, aroma e sabor de ácido cítrico e de fruta, quando comparadas às sensações negativas de aroma, como madeira, cinza e tabaco.

Outro tema importante que vem sendo estudado há pouco mais de dez anos é a influência que o fator altitude exerce sobre as características físicas, químicas e sensoriais do café. Entretanto, existem poucos estudos sobre o assunto e os resultados obtidos até o momento são contraditórios.
A OIC (1991) realizou uma pesquisa com cafés cultivados em diferentes altitudes na região de Patrocínio, no Estado de Minas Gerais, e mediante avaliação sensorial, concluiu-se que a altitude exerce uma grande influência sobre a qualidade da bebida do café, que se manifesta com o aumento da acidez.

Solares et al. (2000), estudando a influência das variedades (Bourbon, Caturra e Catuaí), cultivadas a três níveis de altitude: abaixo de $1220 \mathrm{~m}$, entre $1220 \mathrm{~m}$ a $1460 \mathrm{~m}$ e acima de $1460 \mathrm{~m}$, concluíram ser evidente a influência que o fator altitude exerce sobre a qualidade do café, independente da variedade cultivada. Os autores observaram que as propriedades organolépticas como: corpo, aroma e suavidade acentuam-se à medida que a altitude se eleva, ao passo que para a variável acidez, essa evidência não é tão perceptível.

Em consideração ao exposto, com o presente estudo tem-se como objetivo geral caracterizar física, química e sensorialmente "cafés-cereja descascados" produzidos na região sul de Minas Gerais. Especificamente, buscou-se analisar a influência da altitude e da presença ou ausência de defeitos na composição química dos grãos e nas propriedades sensoriais da bebida do café.

\section{MATERIAL E MÉTODOS}

O preparo das amostras, o armazenamento, a classificação e as análises químicas, físicas e sensoriais foram realizados no Pólo de Tecnologia em Qualidade do Café do Centro de Ensino, Pesquisa e Extensão do Agronegócio Café (CEPECAFÉ) da Universidade Federal de Lavras e no Laboratório da Empresa de Pesquisa Agropecuária de Minas Gerais (EPAMIG), campus da UFLA.

Foram utilizadas amostras de cafés processados pelo método “cereja descascado”, coletadas em 32 propriedades cafeeiras localizadas em 10 municípios da região sul de Minas Gerais.

A seleção das empresas cafeeiras estudadas foi baseada em informações relatadas pelo Instituto Brasileiro de Geografia e Estatística (IBGE), adotando-se os seguintes critérios: a) foram selecionados 10 municípios considerados os maiores produtores de café da região sul de Minas Gerais, e que estão localizados em faixas de altitudes com limites compreendidos entre 720 a 1120 metros; b) quanto à localização geográfica, as lavouras cafeeiras de cada empresa foram enquadradas em duas faixas de altitudes, entre 720 e 920 metros e 920 e 1120 metros, somando-se 16 lavouras por faixa de altitude, totalizando 32 lavouras; c) com auxílio de um altímetro, realizou-se a leitura em três pontos estratégicos em cada lavoura (ponto inferior, mediano e superior); 
em seguida, somaram-se os valores obtidos em cada leitura e calculou-se a média; o resultado foi utilizado como parâmetro para enquadrar a lavoura na faixa de altitude de 720 a 920 metros ou 920 a 1120 metros; d) todas as empresas selecionadas possuíam infraestrutura básica (terreiro pavimentado, lavadorseparador e descascador) para processar o café pelo método cereja descascado.

Durante os meses de julho a dezembro de 2002, foram realizadas visitas técnicas a 32 propriedades cafeeiras para coleta de amostra. A amostragem dos grãos de café (safra 2001-2002) foi realizada, em sua maioria, na forma beneficiada ( $90 \%$ grãos crus) e armazenada em Cooperativas, sendo o restante coletado em pergaminho e armazenado em tulhas na própria fazenda.

As amostras foram coletadas manualmente, em diferentes pontos ou locais dos lotes, em sacos (café beneficiado) ou tulhas (café em pergaminho), com aproximadamente 3 a $5 \mathrm{~kg}$ de café beneficiado e 10 a $12 \mathrm{~kg}$ de café em pergaminho, constituindo uma amostra composta.

As amostras de café em pergaminho foram beneficiadas no CEPECAFÉ (UFLA), sendo, em seguida, embaladas em sacos plásticos, identificadas e armazenadas no Pólo de Tecnologia em Qualidade do Café da UFLA, à temperatura de $\pm 17^{\circ} \mathrm{C}$, por um período aproximado de 1 ano.

Das amostras coletadas em cada propriedade, foram moídas 150 gramas de café cru, divididas em três subamostras de 50 gramas. Para fazer as análises dos grãos com a presença e ausência de defeitos (CDSD), o critério adotado foi o de retirar da amostra original todos os defeitos intrínsecos (grãos verdes, ardidos, conchas, mal granados, brocados e quebrados). O critério adotado para realizar as análises dos grãos com a presença dos defeitos foi o de pesar os 50 gramas sem observar qual tipo de defeito estava presente na amostra.

Para realizar as análises químicas, os grãos crus foram submetidos ao processo de moagem, em moinho bola (modelo Prolabo, Paris), colocando-se sobre a amostra aproximadamente $5 \mathrm{ml}$ de nitrogênio líquido para facilitar o processo de moagem. Em seguida, o café moído foi embalado e armazenado em freezer até o momento da realização das análises.

\section{Análise sensorial}

A classificação sensorial, pela prova de xícara, foi realizada por um provador devidamente credenciado pelo Ministério da Agricultura, que desconhecia a procedência das amostras. O provador analisou e classificou separadamente todas as amostras. Considerando que na mesma amostra foram realizadas análises sensoriais de grãos de café com a presença e ausência dos defeitos intrínsecos (preto, verde, ardido, quebrado, mal granado, etc.), as infusões foram preparadas em seis xícaras e submetidas ao teste de degustação. No preparo da bebida, utilizou-se a torração clara, com \pm 10 gramas de café moído por xícara.

\section{Análises físicas e químicas}

\section{Teor de água}

$\mathrm{O}$ teor de água foi determinado pelo método padrão de secagem em estufa a $105 \pm 3^{\circ} \mathrm{C}$ por um período de 24 horas (BRASIL, 1992). Os resultados obtidos foram expressos em porcentagem de base úmida (b.u.).

\section{Acidez titulável total}

A acidez titulável total foi determinada por titulação com $\mathrm{NaOH}$ a $0,1 \mathrm{~N}$, de acordo com a técnica descrita pela AOAC (1990). Os resultados foram expressos em $\mathrm{mL}$ de $\mathrm{NaOH} 0,1 \mathrm{~N}$ por 100 gramas de amostra.

\section{Açúcares totais e redutores}

Os açúcares totais e redutores foram extraídos pelo método de Lane-Enyon, citado pela AOAC (1990), e determinados pela técnica de Somogy, sendo os resultados expressos em \%.

\section{Delineamento experimental}

Foram estudadas duas altitudes, utilizando-se dados de 16 propriedades em cada faixa de altitude. Avaliaram-se três amostras de café com a presença e ausência de defeitos em cada propriedade.

Para efeito de análise estatística, utilizou-se um delineamento inteiramente ao acaso com três repetições, parcialmente hierarquizado. Consideraram-se o efeito de propriedade hierarquizado nas altitudes e um fatorial 2x2 envolvendo as quatros combinações das altitudes com os defeitos.

\section{RESULTADOS E DISCUSSÃO}

\section{Teor de água (\% b.u.)}

Apresentam-se na Tabela 1 os teores médios de água para as amostras de café-cereja descascado analisadas em cada faixa de altitude. A comparação dos valores médios das amostras analisadas com e sem a presença dos defeitos está apresentada na Tabela 2. 
TABELA 1 - Teores médios de água (\% b.u.) em amostras de café-cereja descascado, cultivado nas faixas de altitude de 720 a 920 metros e de 920 a 1120 metros.

\begin{tabular}{cccc}
\hline \multicolumn{4}{c}{ Altitude (m) } \\
\hline \multicolumn{2}{c}{$\mathbf{7 2 0}-\mathbf{9 2 0}$} & \multicolumn{2}{c}{$\mathbf{9 2 0}$ - 1120 } \\
\hline Amostra & (\% b.u.) & Amostra & (\% b.u) \\
\hline 22 & $9,62 \mathrm{~g}$ & 32 & $9,32 \mathrm{~g}$ \\
25 & $10,04 \mathrm{f}$ & 26 & $9,88 \mathrm{f}$ \\
24 & $10,20 \mathrm{e}$ & 13 & $10,13 \mathrm{e}$ \\
15 & $10,32 \mathrm{e}$ & 19 & $10,25 \mathrm{~d}$ \\
23 & $10,40 \mathrm{e}$ & 16 & $10,37 \mathrm{~d}$ \\
14 & $10,43 \mathrm{e}$ & 18 & $10,39 \mathrm{~d}$ \\
11 & $10,53 \mathrm{~d}$ & 6 & $10,68 \mathrm{c}$ \\
4 & $10,56 \mathrm{~d}$ & 20 & $10,79 \mathrm{c}$ \\
1 & $10,57 \mathrm{~d}$ & 29 & $10,83 \mathrm{c}$ \\
28 & $10,59 \mathrm{~d}$ & 8 & $10,86 \mathrm{c}$ \\
12 & $10,60 \mathrm{~d}$ & 30 & $10,92 \mathrm{c}$ \\
2 & $10,77 \mathrm{c}$ & 3 & $10,94 \mathrm{c}$ \\
9 & $11,08 \mathrm{~b}$ & 27 & $10,98 \mathrm{c}$ \\
5 & $11,11 \mathrm{~b}$ & 7 & $11,42 \mathrm{~b}$ \\
31 & $11,23 \mathrm{~b}$ & 21 & $11,52 \mathrm{~b}$ \\
10 & $11,42 \mathrm{a}$ & 17 & $11,69 \mathrm{a}$ \\
\hline Média & $10,59 \mathrm{~A}$ & Média & $10,68 \mathrm{~B}$ \\
\hline
\end{tabular}

Médias seguidas pela mesma letra minúscula na coluna e letra maiúscula na linha não diferem entre si a 5\% de probabilidade pelo teste de Scott-Knott.

TABELA 2 - Teores médios de água (\% b.u.) em amostras de café-cereja descascado, com a presença e ausência de defeitos.

\begin{tabular}{cc}
\hline \multicolumn{2}{c}{ Teor de água $(\%$ b. u.) } \\
\hline Com defeito & Sem defeito \\
\hline $10,57 \mathrm{~B}$ & $10,71 \mathrm{~A}$ \\
\hline
\end{tabular}

Medias seguidas por letras maiúsculas diferentes na linha diferem entre si a $5 \%$ de probabilidade pelo teste de Scott-Knott.
Observa-se nas Tabelas 1 e 2 que os fatores altitude, amostra dentro de cada nível de altitude e a presença ou ausência de defeitos foram significativos ao nível de $5 \%$ de probabilidade $(\mathrm{P}<0,05)$.

Apesar de as médias dos teores de água por faixa de altitude (Tabela 1) e as médias das amostras com e sem a presença de defeitos (Tabela 2) diferirem significativamente entre si, diferenças inferiores a 0,5 ponto percentual não são consideradas relevantes, uma vez que variações dessa magnitude são toleradas no testepadrão de estufa para determinação de umidade.

No entanto, observa-se na Tabela 1 que o teor de água variou entre 9,32 e 11,69\% b.u. nas amostras coletadas nas diferentes propriedades. Além disso, a maioria apresentou valores inferiores ao teor de água recomendado pelo Ministério da Agricultura, segundo a Instrução Normativa ${ }^{\circ} 08$, de 11 de junho de 2003. Dois fatores podem estar relacionados a esse fato: a condução inadequada do processo de secagem, permitindo uma retirada excessiva de água do café, ou a utilização de métodos e procedimentos empíricos na propriedade para a determinação da umidade final.

A maioria dos produtores realiza secagem combinada, ou seja, pré-secagem por 1 ou 2 dias em terreiros para, em seguida, submeter os grãos a uma secagem complementar em secadores mecânicos. Nessas etapas, diversos fatores, como condições climáticas, condução das operações nos terreiros e o controle da temperatura nos secadores mecânicos podem resultar em maior ou menor retirada de água do produto.

As maiores conseqüências advindas da secagem excessiva são financeiras, considerando a perda de peso dos grãos e a possibilidade de quebra durante o processo de beneficiamento.

\section{Acidez titulável total}

Os valores médios de acidez titulável total para as amostras de café-cereja descascado analisadas em cada faixa de altitude encontram-se na Tabela 3.

Observa-se na Tabela 3 que os valores médios de acidez titulável total diferiram significativamente entre si $(\mathrm{P}<0,05)$ para as duas faixas de altitude estudadas.

Em cada faixa de altitude, ocorreram diferenças significativas $(\mathrm{P}<0,05)$ entre os valores de acidez titulável total das amostras das propriedades, variando de 185,41 a $253,12 \mathrm{~mL}$ de $\mathrm{NaOH} 0,1 \mathrm{~N} 100 \mathrm{~g}^{-1}$ e de 194,74 a $254,16 \mathrm{~mL}$ de $\mathrm{NaOH} 0,1 \mathrm{~N} 100 \mathrm{~g}^{-1}$ respectivamente, para as propriedades localizadas na faixa de altitude de 720 a 920 metros e de 920 a 1120 metros. Observa-se em cada faixa de altitude a ocorrência de grupos de propriedades com valores que diferiram significativa- 
mente entre si. Na faixa de altitude de 720 a 920 metros, ocorreram três grupos distintos entre as propriedades estudadas. As amostras coletadas nas propriedades nas faixas de altitude de 920 a 1120 metros significativamente foram subdivididas em quatros grupos, com valores superiores indicando maior variabilidade para essa variável.

Vários pesquisadores têm buscado métodos químicos para auxiliar a classificação sensorial. Apesar de não ter sido possível estabelecer uma relação direta entre acidez titulável total e as diferentes classes de bebida, em muitos trabalhos de pesquisa tem-se demonstrado que cafés de pior qualidade apresentam maiores valores para essa variável.
Carvalho et al. (1994), analisando amostras previamente classificadas pela bebida, demonstraram a ocorrência de maiores valores de acidez nos cafés de bebida dura, riada e rio, ou seja, respectivamente, 250,4; 272,2 e 284,5 mL de $\mathrm{NaOH} 0,1 \mathrm{~N} 100 \mathrm{~g}^{-1}$. No presente trabalho, o maior valor observado foi de 254,16 $\mathrm{mL}$ de $\mathrm{NaOH} 0,1 \mathrm{~N} 100 \mathrm{~g}^{-1}$. Conforme será descrito posteriormente, não foram encontradas amostras com bebidas classificadas como riada ou rio.

Assim, apesar de ter sido observada diferença significativa entre as médias de acidez titulável total entre altitudes (Tabela 3), acredita-se que o valor final dessa variável está relacionado com diversos outros fatores inerentes aos procedimentos de cada propriedade e não necessariamente com a altitude para a faixa estudada neste trabalho.

TABELA 3 - Valores médios de acidez titulável total (mL de NAOH 0,1N/100 g) em amostras de café-cereja descascado, produzido nas faixas de altitude de 720 a 920 metros e de 920 a 1120 metros.

\begin{tabular}{|c|c|c|c|}
\hline \multicolumn{4}{|c|}{ Altitude (m) } \\
\hline \multicolumn{2}{|c|}{$720-920$} & \multicolumn{2}{|c|}{$920-1120$} \\
\hline Amostra & $\mathrm{mL}$ de $\mathrm{NaOH} 0,1 \mathrm{~N} 100 \mathrm{~g}^{-1}$ & Amostra & mL de $\mathrm{NaOH} 0,1 \mathrm{~N} 100 \mathrm{~g}^{-1}$ \\
\hline 15 & $185,41 \mathrm{c}$ & 32 & $194,74 \mathrm{~d}$ \\
\hline 24 & 191,66 c & 7 & $200,00 \mathrm{~d}$ \\
\hline 11 & $192,70 \mathrm{c}$ & 19 & $202,08 \mathrm{~d}$ \\
\hline 14 & 192,70 c & 6 & $202,08 d$ \\
\hline 2 & $193,75 \mathrm{c}$ & 3 & $206,25 d$ \\
\hline 12 & 195,83 c & 13 & $213,54 \mathrm{c}$ \\
\hline 10 & $205,20 \mathrm{~b}$ & 8 & 216,66 c \\
\hline 9 & $208,33 \mathrm{~b}$ & 27 & 218,75 c \\
\hline 5 & 209,37 b & 17 & 221,87 c \\
\hline 4 & $211,45 \mathrm{~b}$ & 20 & $230,20 \mathrm{~b}$ \\
\hline 23 & $212,50 \mathrm{~b}$ & 26 & $231,25 \mathrm{~b}$ \\
\hline 22 & $214,58 b$ & 16 & $235,41 \mathrm{~b}$ \\
\hline 28 & 237,41 a & 30 & 241,66 b \\
\hline 25 & 238,12 a & 29 & 250,95 a \\
\hline 31 & 247,87 a & 18 & 251,04 a \\
\hline 1 & 253,12 a & 21 & 254,16 a \\
\hline Média & $221,88 \mathrm{~B}$ & Média & $223,17 \mathrm{~A}$ \\
\hline
\end{tabular}

Médias seguidas pela mesma letra minúscula na coluna e letra maiúscula na linha não diferem entre si a $5 \%$ de probabilidade pelo teste de Scott-Knott. 


\section{Açúcares totais}

Os teores médios de açúcares totais das amostras de café-cereja descascado das diferentes propriedades em cada faixa de altitude, com a presença e ausência de defeitos, são apresentados na Tabela 4 e 5, respectivamente.

TABELA 4 - Valores médios de açúcares totais (\%) em amostras de café-cereja descascado, cultivado nas faixas de altitude de 720 a 920 metros e de 920 a 1120 metros.

\begin{tabular}{cccc}
\hline \multicolumn{5}{c}{ Altitude (m) } \\
\hline \multicolumn{4}{c}{ 920 - 1120 } \\
\hline 720 - 920 & Açcares Totais \\
\hline Amostra & $\mathbf{( \% )}$ & Amostra & $\mathbf{( \% )}$ \\
\hline 10 & $8,63 \mathrm{~b}$ & 6 & $8,62 \mathrm{~b}$ \\
5 & $8,67 \mathrm{~b}$ & 8 & $9,04 \mathrm{~b}$ \\
1 & $8,89 \mathrm{~b}$ & 16 & $9,13 \mathrm{~b}$ \\
23 & $8,91 \mathrm{~b}$ & 7 & $9,17 \mathrm{~b}$ \\
4 & $9,16 \mathrm{~b}$ & 17 & $9,22 \mathrm{~b}$ \\
14 & $9,18 \mathrm{~b}$ & 18 & $9,23 \mathrm{~b}$ \\
2 & $9,19 \mathrm{~b}$ & 3 & $9,32 \mathrm{~b}$ \\
12 & $9,21 \mathrm{~b}$ & 20 & $9,32 \mathrm{~b}$ \\
28 & $9,27 \mathrm{~b}$ & 29 & $9,36 \mathrm{~b}$ \\
9 & $9,42 \mathrm{~b}$ & 30 & $9,38 \mathrm{~b}$ \\
31 & $9,75 \mathrm{a}$ & 19 & $9,42 \mathrm{~b}$ \\
22 & $9,75 \mathrm{a}$ & 13 & $9,44 \mathrm{~b}$ \\
24 & $9,80 \mathrm{a}$ & 26 & $9,76 \mathrm{a}$ \\
11 & $9,81 \mathrm{a}$ & 27 & $9,93 \mathrm{a}$ \\
15 & $9,84 \mathrm{a}$ & 32 & $9,99 \mathrm{a}$ \\
25 & $10,15 \mathrm{a}$ & 21 & $10,12 \mathrm{a}$ \\
\hline
\end{tabular}

Médias seguidas pela mesma letra minúscula na coluna não diferem entre si a $5 \%$ de probabilidade pelo teste de Scott-Knott.

Apesar de alguns autores afirmarem que o local de cultivo (LEITE, 1991) e a altitude (GUYOT et al., 1986) influenciam o teor de açúcares totais, no presente trabalho, observaram-se para essa variável diferenças significativas somente entre os valores médios das amostras provenientes das diferentes propriedades, não sendo observada diferença entre as faixas de altitude estudadas.
Os valores médios de açúcares totais relatados para os cafés-cereja descascado do sul de Minas variam de 8 a 10\% (VILLELA, 2002).

Barrios (2001), Pinto (2002) e Villela (2002) encontraram valores médios de açúcares totais em cafés considerados de bebida mole, apenas mole e estritamente mole em torno de 9,90\%, 8,62 e 9,27\%, respectivamente.

Os açúcares totais são os componentes que mais contribuem para a formação do aroma e sabor do café torrado (SIVETZ, 1963). Sendo assim, valores mais elevados de açúcares podem indicar a presença de maior doçura na bebida, pois, durante a torração, a sacarose, que é o açúcar presente em maior quantidade, é degradada, sendo utilizada nas reações de Maillard e caramelização, que originam vários compostos voláteis e nãovoláteis.

Segundo a OIC (1991), a doçura é uma característica de sabor desejável nos cafés especiais, e a presença de certos compostos orgânicos no grão cru serve como substratos para diversas reações que culminaram na definição dos padrões qualitativos da bebida. A OIC (1992) cita que os açúcares são responsáveis pela formação do sabor caramelo identificado na bebida do café.

Os valores de açúcares totais obtidos no presente trabalho são próximos aos dos autores acima citados. Considerando-se as observações de Sivetz (1963) e da OIC (1991, 1992), os valores obtidos reforçam e subsidiam os relatos de vários pesquisadores e empresas de comercialização sobre o alto potencial de produção de cafés de boa qualidade da região sul de Minas.

Os teores médios de açúcares totais das amostras de café-cereja descascado com a presença e a ausência de defeitos em cada faixa de altitude são apresentados na Tabela 5.

TABELA 5 - Valores médios dos teores de açúcares totais (\%) em amostras de café-cereja descascado, com a presença e a ausência de defeitos nas faixas de altitude de 720 a 920 metros e de 920 a 1120.

\begin{tabular}{ccc}
\hline \multicolumn{3}{c}{ Altitude (m) } \\
\hline & $\mathbf{7 2 0} \mathbf{- 9 2 0}$ & $\mathbf{9 2 0}-\mathbf{1 1 2 0}$ \\
\hline Sem defeito & $9,74 \mathrm{aA}$ & $10,23 \mathrm{aA}$ \\
\hline Com defeito & $8,97 \mathrm{bA}$ & $8,58 \mathrm{bA}$ \\
\hline
\end{tabular}

Médias seguidas pela mesma letra minúscula na coluna e mesma letra maiúscula na linha não diferem entre si a 5\% de probabilidade pelo teste de Scott-Knott. 
Miya et al. (1973/1974), Pereira (1997) e Coelho (2000) observaram um decréscimo significativo na qualidade da bebida com a inclusão de defeitos verdes, pretos e ardidos. No presente trabalho, observou-se uma redução significativa $(\mathrm{P}<0,05)$ nos valores médios de açúcares totais com a presença de defeitos. O acúmulo desses açúcares, no entanto, foi mais evidente na faixa de altitude de 920 a 1120 metros com a retirada dos defeitos. Sendo assim, o valor médio mais elevado de açúcares para as amostras de café cultivados nessa faixa de altitude deve-se provavelmente a uma influência positiva do local de cultivo, resultando em um maior período de maturação dos frutos, bem como em uma menor ocorrência de frutos verdes, imaturos e defeituosos.

\section{Classificação da bebida}

A classificação oficial brasileira para o café beneficiado (Instrução Normativa $\mathrm{N}^{\circ}$ 08, de 11 de junho de 2003 do Ministério da Agricultura) determina que esse café seja classificado em Categorias, Subcategoria, Grupos, Subgrupo, Classe e Tipo.

Entre todas essas classificações, no presente estudo trabalhou-se apenas com a categoria I, que se refere a cafés provenientes da espécie Coffea arabica L. e com o grupo I arábica, que, de acordo com a bebida, foi classificado em dois subgrupos: bebidas finas (estritamente mole, mole, apenas mole, duro) e bebidas fenicadas (riado, rio e rio zona).

Os valores percentuais para os diferentes atributos característicos da bebida, acidez, corpo e doçura do cafécereja descascado com a presença e ausência dos defeitos, cultivados nas faixas de altitude de 720 a 920 metros e de 920 a 1120 metros, estão mostrados na Tabela 6.

Comparando os valores percentuais de acidez entre ambas as faixas de altitudes, observa-se uma maior freqüência de acidez classificada como média e alta com a presença dos defeitos. Entretanto, essa freqüência diminui consideravelmente com a retirada dos defeitos na faixa de altitude de 920 a 1120 metros, ocorrendo 31\% de amostras classificadas com acidez baixa.

TABELA 6 - Valores percentuais para os diferentes atributos característicos da bebida, acidez, corpo e doçura do café-cereja descascado com a presença e ausência dos defeitos, cultivados nas faixas de altitude de 720 a 920 metros e de 920 a 1120 metros.

\begin{tabular}{|c|c|c|c|c|c|}
\hline \multicolumn{6}{|c|}{ Altitude (m) } \\
\hline \multicolumn{3}{|c|}{$720-920$} & \multicolumn{3}{|c|}{$920-1120$} \\
\hline \multicolumn{2}{|c|}{ Sem defeito } & \multirow{2}{*}{$\begin{array}{c}\text { Com defeito } \\
(\%) \\
\end{array}$} & \multicolumn{2}{|c|}{ Sem defeito } & \multirow{2}{*}{$\begin{array}{c}\text { Com defeito } \\
(\%) \\
\end{array}$} \\
\hline Acidez & $(\%)$ & & Acidez & $(\%)$ & \\
\hline Alta & 6 & 6 & Alta & 31 & 25 \\
\hline Média & 75 & 81 & Média & 38 & 69 \\
\hline Baixa & 19 & 13 & Baixa & 31 & 6 \\
\hline Total & 100 & 100 & Total & 100 & 100 \\
\hline Corpo & & & Corpo & & \\
\hline Alto & 13 & 13 & Alto & 32 & 12 \\
\hline Médio & 75 & 87 & Médio & 12 & 82 \\
\hline Baixo & 12 & - & Baixo & 56 & 6 \\
\hline Total & 100 & 100 & Total & 100 & 100 \\
\hline Doçura & & & Doçura & & \\
\hline Alta & 38 & 31 & Alta & 63 & 37 \\
\hline Média & 62 & 62 & Média & 37 & 56 \\
\hline Baixa & - & 7 & Baixa & - & 7 \\
\hline Total & 100 & 100 & Total & 100 & 100 \\
\hline
\end{tabular}


Na faixa de altitude de 720 a 920 metros, mesmo com a retirada dos defeitos, ainda observa-se uma elevada porcentagem de amostras com acidez média (75\%) e alta (6\%).

Na faixa de altitude de 720 a 920 metros, $100 \%$ das amostras com defeito foram classificadas como de corpo médio e alto, ocorrendo, na faixa de altitude de 920 a 1120 metros, $6 \%$ das amostras com corpo baixo. Se, por um lado, a retirada dos defeitos aumentou para $56 \%$ a quantidade de bebida com corpo baixo na altitude de 920 a 1120 metros, por outro lado, na faixa de altitude de 720 a 920 metros, a maioria das amostras permaneceu com características de corpo médio e alto.

No atributo doçura, observa-se que a retirada dos defeitos proporcionou a ocorrência de uma maior porcentagem de amostras classificadas com doçura alta (63\%) na faixa de altitude de 920 a 1120 metros, comparativamente à faixa de altitude de 720 a 920 metros, na qual ocorreu apenas em 38\% das amostras com doçura alta.

Assim, a combinação dos atributos acidez baixa, corpo baixo e doçura alta observadas nas amostras, sem os defeitos na faixa de 920 a 1120 metros, indica que os cafés produzidos nessa altitude apresentam potencialmente melhores características para obtenção de bebida finas.

\section{CONCLUSÕES}

a) A maioria das amostras dos cafés-cereja descascados apresenta teores de água abaixo do valor recomendado.

b) Os valores médios de acidez titulável total e açúcares totais, em todas as amostras analisadas, encontram-se dentro dos valores característicos de bebidas finas.

c) Os cafés sem a presença dos defeitos, produzidos na faixa de 920 a 1120 metros, apresentam corpo e acidez mais fracos e doçura mais alta do que os produzidos na faixa de 720 a 920 metros.

d) Maiores altitudes possibilitam a produção de cafés de melhor qualidade.

\section{REFERÊNCIAS BIBLIOGRÁFICAS}

ASSOCIATION OF OFFICIAL ANALITICAL CHEMISTS. Official methods of analysis of the Association of Official Analytical Chemists. 15. ed. Washington, 1990. $2 \mathrm{v}$.
BARRIOS, B. B. E. Caracterização física, química, microbiológica e sensorial de cafés (Coffea arábica L.) da região Alto Rio Grande - Sul de Minas Gerais. 2001. 72 p. Dissertação (Mestrado em Ciência dos Alimentos) - Universidade Federal de Lavras, Lavras, 2001.

BRANDO, C. H. J. Métodos de colheita e pós-colheita para a preservação da qualidade do produto em cultivos com alta densidade. In: SIMPÓSIO INTERNACIONAL SOBRE CAFÉ ADENSADO, 1994, Londrina, PR. Anais... Londrina: IAPAR, 1996. p. 231-247.

BRASIL. Ministério da Agricultura e Abastecimento. Instrução normativa $\mathbf{n}^{\mathbf{0}} \mathbf{8}$, de 11 de junho de 2003. Aprova o regulamento técnico da identidade e de qualidade para a classificação de café beneficiado grão cru, em anexo. Ministério de Estado, Interino da Agricultura, Pecuária e Abastecimento. Disponível em: <http://www.ministério.gov.com.br>. Acesso em: 20 ago. 2003.

BRASIL. Ministério da Agricultura e Reforma Agrária. Regras para análise de semente. Brasília: CLAV/DNDV/SAND/MA, 1992. 365 p.

CARVALHO, V. D. et al. Relação entre a composição físico-química e química do grão do café beneficiado e a qualidade de bebida do café. Pesquisa Agropecuária Brasileira, Brasília, v. 29, n. 3, p. 449-454, mar. 1994.

COELHO, K. F. Avaliação química e sensorial da qualidade do café de bebida estritamente mole após a inclusão de grãos defeituosos. 2000. 96 p. Dissertação (Mestrado em Ciência dos Alimentos) - Universidade Federal de Lavras, Lavras, 2000.

GUYOT, B. et al. Influence de 1'altitude et de 1 'ombrage sur la qualité des cafes Arabica. Plantations, Recherche, Devoloppement, Paris, v. 3, n. 4, p. 272-283, juil/août 1996.

LEITE, I. P. Influência do Local de cultivo e do tipo de colheita nas características físicas, composição química do grão e Qualidade do café (Coffea arábica L.). 1991. 131 f. Dissertação (Mestrado em Ciência dos Alimentos) - Escola Superior de Agricultura de Lavras, Lavras, 1991.

MIYA, E. E. et al. Defeito do café e a qualidade da bebida. Coletânea do Instituto de Tecnologia de Alimentos, Campinas, v. 5, p. 417-432, 1973/1974. 
ORGANIZATION INTERNATIONAL DEL CAFÉ. Estúdios de investigacion de evaluacion sensorial sobre la calidad del café cultivado em la region de Patricinio em el Estado de Minas Gerais em Brasil. Londres, 1991. 28 p. (Report de Evaluacion Sensorial).

ORGANIZACIÓN INTERNACIONAL DEL CAFÉ. El despulpado del café por medio de desmucilaginadoras mecanicas sin processo de fermentación y su efecto en la calidad de bebida de café producido en la región de Apucarana en el Estado de Paraná em Brasil. Londres, 1992. não paginado. (Reporte de Evaluación Sensorial).

PEREIRA, R. G. F. A. Efeito da inclusão de grãos defeituosos na composição química e qualidade do café (Coffea arábica L.) "estritamente mole". 1997. 96 f. Tese (Doutorado em Ciência dos Alimentos) - Universidade Federal de Lavras, Lavras, 1997.
PINTO, N. A. V. D. Avaliação química e sensorial de diferentes padrões de bebida do café arábica cru e torrado. 2002. 92 p. Tese (Doutorado em Ciência dos Alimentos) - Universidade Federal de Lavras, Lavras, 2002.

SIVETZ, M. Coffee processing technology. Westport: AVI, 1963. v. 2.

SOLARES, P. F. et al. Influencia de la variedade y la altitude en las características organolépticas y físicas del café. In: SIMPOSIO LATINOAMERICANO DE CAFICUltURA, 19., 2000, Costa Rica. Resumo... Costa Rica: [s.n.], 2000. p. 493-499.

VILLELA, T. C. Qualidade do café despolpado, desmucilado, descascado e natural, durante o processo de secagem. 2002. 66 p. Dissertação (Mestrado em Ciências dos Alimentos) - Universidade Federal de Lavras, Lavras, 2002. 